\title{
Autopercepção de pessoas com deficiência intelectual sobre deficiência, estigma e preconceito
}

\author{
Self-perceotion of people with intelectual disability about disability, stigma \\ and prejudice
}

\author{
Autopercepción de personas con discapacidad intelectual sobre \\ discapacidad, estigma y prejuicio
}

\section{Joab Grana Reis}

Professora doutora na Universidade Estadual do Amazonas, Amazonas, Manaus, Brasil. joabgrana1@gmail.com

ORCID - https://orcid.org/0000-0001-8560-1850

\section{Suéllen Melo Araújo}

Mestranda na Universidade do Estado do Rio de Janeiro, Rio de Janeiro, Rio de Janeiro, Brasil. suellenmelo.a@gmail.com

ORCID - https://orcid.org/0000-0001-7778-2918

\section{Rosana Glat}

Professora doutora na Universidade do Estado do Rio de Janeiro, Rio de Janeiro, Rio de Janeiro, Brasil. rosanaglat@gmail.com

ORCID - https://orcid.org/0000-0002-0186-1342

Recebido em 24 de julho de 2018

Aprovado em 12 de agosto de 2019

Publicado em 12 de novembro de 2019

\section{RESUMO}

Este estudo, que é um recorte da pesquisa "Falando de si: estudos sobre autopercepção e histórias de vida de pessoas com deficiência intelectual", tem como objetivo compreender como pessoas com deficiência intelectual se sentem em relação ao estigma, preconceito e reconhecimento da deficiência. Trata-se de uma pesquisa qualitativa, a partir do levantamento de produções científicas sobre autopercepção de pessoas com deficiência intelectual. Do conjunto foram selecionados cinco textos e, a partir das falas registradas dos sujeitos destacaram-se as categorias: estigma, deficiência e preconceito. Os resultados apontam que ainda são relativamente escassos os estudos que tratam da autopercepção de pessoas com deficiência intelectual. Além disso, apresentam poucos trechos das falas dos sujeitos entrevistados. No que se refere ao estigma, os sujeitos relatam que os outros têm baixa expectativa em relação ao seu potencial, exemplificando a marca da incapacidade construída pelo estereótipo da deficiência. No entanto, as narrativas mostram a resistência destes sujeitos em aceitar o rótulo que lhes foi imputado. É notório a presença do discurso socialmente produzido da deficiência em suas falas, todavia, desenvolvem diferentes estratégias para lidar com o estereótipo. Os relatos sobre suas relações sociais, em sua maioria, evidenciam preconceito, segregação e tratamento hostil, mas também há exemplos de acolhimento e respeito. As falas analisadas representam um indício de que gradativamente essas pessoas estão se colocando como protagonistas de suas vidas, e 
http://dx.doi.org/10.5902/1984686X33882

apontam para a demanda de pesquisas que privilegiem a escuta que legitime as vozes das pessoas com deficiência intelectual.

Palavras-chave: Deficiência intelectual; Autopercepção; Estigma.

\section{ABSTRACT}

This study, which is part of the research "Talking about oneself: studies about selfperception and life histories of people with intellectual disability" aims to understand how people with intellectual disability feel about stigma, prejudice and the knowledge of their disability. It is a qualitative research, based on a survey of scientific productions about selfperception of people with intellectual disability. From the sample were selected five texts and from the registered speeches of the subjects were highlighted the categories: stigma, disability and prejudice. The results indicate that the studies that deal with self-perception of people with intellectual disability are still relatively scarce. Furthermore, they present very few excerpts of the subjects' words during the interviews. Regarding stigma, the subjects report that other people have low expectations about their potential, which exemplifies the fragility mark constructed by the disability stereotype. However, the narratives show these subjects resistance in accepting the label that was given. It is notorious the socially produced iscourse about disability, but they develop different strategies to deal with the stereotype. The reports about their social relations, in the majority of the cases, point to prejudice, segregation and hostile treatment, but there are also examples of acceptance and respect. The speeches analyzed represent a clue that gradually these people are placing themselves as protagonists of their own lives, and point to the need of more researches that focus and legitimize the voices of people with intellectual disability.

Keywords: Intellectual disability; Self-perception; Stigma.

\section{RESUMEN}

Este estudio, que es un recorte de la investigación "Hablando de sí: estudios sobre autopercepción y historias de vida de personas con discapacidad intelectual", tiene como objetivo comprender cómo las personas con discapacidad intelectual se sienten en relación con el estigma, prejuicio y la discapacidad. Se trata de una investigación cualitativa, a partir del levantamiento de producciones científicas sobre autopercepción de personas con discapacidad intelectual. En el conjunto se seleccionaron cinco textos y mediante las declaraciones registradas de los sujetos se destacaron las categorías: estigma, deficiencia y prejuicio. Los resultados apuntan que todavía son relativamente escasos los estudios que tratan de la autopercepción de personas con discapacidad intelectual. Además, presentan pocos fragmentos de las palabras de los sujetos entrevistados. Concerniente al estigma, los sujetos relatan que los demás tienen baja expectativa en relación a su potencial, ejemplificando la marca de la incapacidad construida por el estereotipo de la deficiencia. Aunque, las narrativas muestran la resistencia de estos sujetos a aceptar la etiqueta que les fue imputada. Es notorio la presencia del discurso socialmente producido de la deficiencia en sus palabras, empero, desarrollan diferentes estrategias para lidiar con el estereotipo. Los relatos sobre sus relaciones sociales, en su mayoría, evidencian prejuicio y trato hostil, pero también hay ejemplos de acogida y respeto. Las palabras analizadas representan indicio de que gradualmente esas personas se están poniendo como protagonistas de sus vidas y apuntan a la demanda de investigaciones que privilegien la escucha que legitime las voces de las personas con discapacidad intelectual.

Palabras clave: Discapacidad intelectual; Autopercepción; Estigma. 
http://dx.doi.org/10.5902/1984686X33882

\section{Introdução}

Apesar da disseminação das políticas e ações afirmativas em prol dos direitos de pessoas com deficiência, estas ainda encontram inúmeras barreiras para sua efetiva inclusão educacional e social. No caso dos sujeitos com deficiência intelectual, prevalece a representação social da incapacidade, contribuindo para uma autoimagem inferiorizada, bem como limitada autonomia e participação social.

No que tange a produção científica, ainda são relativamente escassos estudos que privilegiam a voz e a vivência das pessoas com deficiência. No entanto, políticas e práticas de inclusão são operacionalizadas e direcionadas a pessoas reais em suas inter-relações nos diferentes espaços sociais, logo, os sujeitos que as vivenciam são as mais importantes fontes de dados para avaliar os efeitos dessas políticas (GLAT, 2015). Diante disso, entende-se, neste texto, que o conhecimento das suas histórias de vida será fator impulsionador do desenvolvimento de programas que contribuam para que esses indivíduos possam usufruir de uma melhor qualidade de vida, estabelecendo relações pessoais mais equânimes e participando com maior autonomia nos diversos espaços sociais.

O presente artigo apresenta um recorte da pesquisa Falando de si: estudos sobre autopercepção e histórias de vida de pessoas com deficiência intelectual ${ }^{1}$, na qual foi realizado um levantamento da produção nacional sobre autopercepção de pessoas com deficiência intelectual, no período de 2006 a 2016. No âmbito deste texto objetivamos compreender, a partir das falas de jovens e adultos com deficiência intelectual destacadas nos estudos analisados, sua autopercepção em relação à deficiência, ao estigma e ao preconceito.

\section{Problematizando a deficiência como uma produção social}

O ser e estar no mundo para o homem perpassa pelas dimensões biológicas, culturais, sociais e econômicas as quais influenciam diretamente as transformações na organização da sociedade, em diferentes conjunturas históricas. Como lembra Velho (1985, p. 24), o uso e aperfeiçoamento das ferramentas, o estabelecimento de moradias permanentes, a organização familiar, aliados ao "desenvolvimento e dependência dos símbolos significantes (linguagem, arte, mito, ritual)" se constituíram como alguns fatores propulsores para mudanças na relação - indivíduo, sociedade e natureza. 
http://dx.doi.org/10.5902/1984686X33882

Transformações nas dinâmicas sociais são, inevitavelmente, acompanhadas pela produção de normas e valores frente às quais o indivíduo poderá ser "aceito" ou "rejeitado", dependendo das exigências do processo sociocultural instituído em cada comunidade. Essas exigências resultam, frequentemente, na marginalização e exclusão (real e/ou simbólica) de diversos grupos de pessoas que, devido às suas características físicas, intelectuais, de desenvolvimento, culturais, de gênero, etnia, sofrem diferentes formas de desigualdade e preconceito.

Estas marcas negativas construídas socialmente constituem o estigma. Segundo Goffman (2008, p.11), este termo originalmente se referia aos "sinais corporais com os quais se procurava evidenciar alguma coisa de extraordinário ou mau sobre o status moral de quem os apresentava".

A produção do estigma desencadeia um processo que Glat (2006, p.21) denomina de "seleção natural social", a qual assume diferentes formas perversas de exclusão e marginalização de pessoas ou comunidades. O "outro", que não se enquadra no padrão estabelecido socialmente, é o anormal (fora da norma) e acaba sofrendo alguma forma nociva de tratamento de acordo com a categorização estigmatizada (deficiente, negro, índio, judeu, homossexual, etc.) que lhe é atribuída.

[...] os indivíduos desviantes, que por alguma razão, não conseguem se adaptar às normas ou valores da cultura vigente em sua comunidade - que não sobrevivem, portanto, à "seleção social" - são considerados (anormais), e, consequentemente, isolados e marginalizados (GLAT, 2006, p. 23).

Nesse processo de seleção social são produzidas diferentes formas de estigmatização para cada sujeito ou grupo considerado desviante com base na lógica do padrão local de normalidade. Dentre os diversos grupos assim categorizados, o presente artigo tem como foco pessoas com deficiência intelectual cujas vivências e experiências têm sido historicamente marcadas, nas mais diferentes culturas e épocas, pelo estigma, exclusão e descrédito social.

Em termos gerais, a deficiência intelectual é uma condição caracterizada por limitações significativas no funcionamento intelectual global, acompanhada por dificuldades acentuadas no comportamento adaptativo, que se expressa nas habilidades conceituais, sociais e práticas, originando-se antes dos 18 anos de idade (AAIDD, 2010; FONTES; PLETSCH; BRAUN \& GLAT, 2015; REDIG, 2016).

Vale ressaltar que as novas conceituações de deficiência intelectual expandem a definição para além das habilidades cognitivas, medidas por testes de inteligência, 
http://dx.doi.org/10.5902/1984686X33882

considerando outras dimensões do comportamento adaptativo, como habilidades práticas e sociais ${ }^{2}$. Entretanto, esta condição ainda é vista de forma estereotipada e numa perspectiva biomédica como critério referencial para determinar a capacidade cognitiva e possibilidade de desenvolvimento global do indivíduo.

Embora, sem negar que há diferenças significativas no desenvolvimento desses sujeitos que afetam sua aquisição de conhecimentos e adaptação social, comparado com pessoas da mesma faixa etária, corroboramos com a posição de Omote (1994) ao problematizar que a deficiência é, em grande parte, uma produção social:

A deficiência não pode ser vista como uma qualidade presente no organismo da pessoa ou no seu comportamento. [...] é necessário incluir as reações das pessoas como parte integrante e crucial do fenômeno, pois são essas reações que, em última instancia, definem alguém como deficiente (OMOTE, 1994, p. 67 e 68).

Glat (2006), acrescenta:

[...] que o ponto básico para se analisar a questão da deficiência é que o rótulo de deficiente é outorgado ao indivíduo, não apenas em função de suas características orgânicas, mas, sobretudo do papel social que ele representa (GLAT, 2006, p. 28, grifo da autora).

A compreensão da deficiência como um fenômeno psicossocial (FÉDIDA, 1984; GLAT, 2006, 2009; CARNEIRO, 2007; GESSER; NUERNBERG; TONELI, 2012; CASTANHEIRA, 2014) provocou um movimento de desconstrução do chamado modelo médico em que a deficiência era diagnosticada exclusivamente em termos orgânicos. Esta perspectiva tem se materializado em documentos orientadores, como a Convenção dos Direitos das Pessoas com Deficiência (BRASIL, 2011), que em seu preambulo ressalta:

Reconhecendo que a deficiência é um conceito em evolução e que a deficiência resulta da interação entre pessoas com deficiência e as barreiras devidas às atitudes e ao ambiente que impedem a plena e efetiva participação dessas pessoas na sociedade em igualdade de oportunidades com as demais pessoas (BRASIL, 2011, p. 24, grifo nosso).

Não há dúvida de que nas últimas décadas vem ocorrendo uma evolução política, conceitual e social no reconhecimento dos direitos e possibilidades de participação social das pessoas com deficiências. O movimento de inclusão escolar, apesar de todas as contradições e barreiras, vem efetivando a escolarização no sistema comum de ensino de estudantes com deficiência intelectual na Educação Básica, e até mesmo no Ensino Superior. Também vem se abrindo maiores possibilidades para a sua inclusão no mundo do trabalho e em outros espaços sociais. 
http://dx.doi.org/10.5902/1984686X33882

Entretanto, apesar das recentes políticas e ações afirmativas, o imaginário social sobre pessoas com deficiência intelectual ainda é permeado de preconceitos. Como lembra Carneiro (2007, p.182) “[...] não podemos esquecer que eles se constituíram numa sociedade excludente, preconceituosa, onde a visão hegemônica acerca da deficiência, ainda é organicista, focada nos sujeitos que trazem marcas significadas como limites e impossibilidades".

$E$ é ainda nessa realidade sociocultural estigmatizante que as pessoas com deficiência constroem sua identidade e assumem seu lugar no mundo nas diferentes fases de sua vida. Esse processo de socialização estereotipada reflete, frequentemente, em uma autoimagem $^{3}$ depreciativa, na medida em que o indivíduo acaba se identificando com o papel que Ihe foi outorgado. Consciente ou inconscientemente, "ele passa a ver a si próprio como se não fosse nada além de um deficiente" (GLAT, 2006, p. 31), e é assim tratado pelos demais, inclusive sua família.

Justamente, em função da desvalorização da capacidade de articulação de pessoas com deficiência intelectual, sua visão de mundo "raramente é levada em consideração na elaboração de teorias a respeito da deficiência ou no planejamento de programas de atendimento" (GLAT, 2006, p. 26). Entretanto, a partir da escuta respeitosa de suas vozes, poderemos compreender sua realidade e criar políticas e demais mecanismos para favorecer sua inclusão social.

\section{Procedimentos metodológicos}

Conforme mencionado, este texto é um recorte de um estudo que catalogou e examinou pesquisas nacionais sobre autopercepção de pessoas com deficiência intelectual envolvendo diferentes aspectos de suas vidas, através de seus relatos pessoais, ou seja, trata-se da "história contada por quem a vivenciou" (SPINDOLA; SANTOS, 2003). As produções selecionadas englobam o período de 2006 a 2016, tendo como marco temporal inicial a promulgação da Convenção dos Direitos das Pessoas com Deficiência (ONU, 2006) $)^{4}$. O levantamento das pesquisas ocorreu por meio de consulta realizada nos bancos de dados da CAPES, Scielo, Revista Brasileira de Educação Especial (vinculada à Associação Brasileira de Pesquisadores em Educação Especial - ABPEE), Revista de Educação Especial (Universidade Federal de Santa Maria) e Dossiê de Educação Especial da Revista Interfaces da Educação (Universidade Estadual do Mato Grosso do Sul). 
http://dx.doi.org/10.5902/1984686X33882

Para a busca nos referidos bancos de dados, foi estabelecido um conjunto de descritores: a) deficiência intelectual - mental; b) história de vida; c) autopercepção; d) relatos pessoais; e) autodefensoria; f) subjetividade; g) identidade; h) autoconceito; i) autoadvocacia; j) autogestão. Tais palavras-chave foram pesquisadas de maneira agrupada, ou seja, em duplas e/ou trios com objetivo de encontrar o maior número de textos que pudessem estar relacionados.

Desse levantamento foram considerados 19 estudos que atendiam os objetivos da pesquisa Falando de si. O critério estabelecido para a seleção dessas produções consistiu na presença dos registros das falas de pessoas com deficiência intelectual. Todos esses estudos foram lidos na íntegra, porém a análise levou em consideração exclusivamente as falas dos sujeitos, partir das quais foram construídas categorias, a saber: família, escola, trabalho, lazer, planos para o futuro, relacionamentos, atividades de vida diária, estigma, deficiência e preconceito. Tal procedimento metodológico fundamenta-se no método de História de Vida, que considera como única fonte de dados, a estória ou relato de vida de cada sujeito, entrevistado.

No âmbito deste artigo estaremos analisando as categorias estigma, deficiência e preconceito, devido à inter-relação dos aspectos psicossociais que as perpassam. Estas categorias foram identificadas em cinco das 19 pesquisas integrantes do banco de dados do estudo. Entre essas se encontram duas teses de doutorado (CARNEIRO, 2007; ANTUNES, 2012), duas dissertações de mestrado (SODELLI, 2010; CASTANHEIRA, 2014) e um artigo publicado em periódico (LOPES, 2012).

\section{Análise e discussão dos dados}

Antes de iniciar a discussão das referidas categorias, é importante tecer duas observações gerais do estudo. Primeiramente, o levantamento mostrou que ainda são relativamente escassos, no conjunto da produção científica, pesquisas que tratam da autopercepção de pessoas com deficiência intelectual, ou seja, que evidenciem suas vivências e experiências, a partir da narração dos próprios sujeitos. Isto, provavelmente, é produto da dinâmica das relações socioculturais estabelecidas com este público, que ainda é marcada por uma visão estigmatizada desses indivíduos como incapazes de "avaliar sua problemática, suas necessidades e expectativas" (GLAT, 2009, p. 25).

Verificamos, também, que grande parte dos estudos analisados, mesmo com 0 objetivo de ouvir os sujeitos, apresentam poucos registros de suas falas, e mais as 
http://dx.doi.org/10.5902/1984686X33882

interpretações dos autores sobre as mesmas. De modo geral, nas produções acadêmicas, teses e dissertações, encontra-se um maior quantitativo de depoimentos dos entrevistados. Já nos artigos, talvez, por limitação de espaço, somente alguns poucos trechos reproduzem a narrativa dos sujeitos.

De acordo com Nunes et al. (2002, p. 138), a escuta dos próprios indivíduos com deficiência intelectual possibilita rupturas de paradigmas científicos significativos, e "[...] representa uma mudança radical do objeto de estudo e da própria relação do pesquisador com o sujeito, já que se deixa de analisar a doença ou o desvio para compartilhar sua vida".

\section{Autopercepção do estigma}

Compreender que a deficiência é, em grande parte, uma produção social, coloca em cheque a visão ainda predominante que se expressa no estigma da incapacidade. Este estigma materializa-se em prática social excludente, vivenciada pelas pessoas com deficiência intelectual, em seu cotidiano, como descrédito social.

Como mencionado, estigma é uma marca construída socialmente para classificar os indivíduos considerados desviantes. Nunes et al. (2002) indicam que:

A partir do momento em que um indivíduo é rotulado, frequentemente através de um diagnóstico de "excepcional", todas as suas atitudes e comportamentos, assim como sua expressão de subjetividade, passam a ser vistas sob a ótica da "anormalidade" (NUNES et al., 2002, p.136).

A autopercepção dessa prática social demarcada pelo estigma da incapacidade ficou evidenciada na fala de alguns sujeitos das pesquisas analisadas, como ilustrado a seguir:

Tenho dúvida por que com Síndrome de Down não pode dirigir. Por que as pessoas olham pra você e não sabe o que vai falar? Um monte de coisas, que eu levo estas questões para mim. Eu vou trabalhar com isso. (Ana Carolina, ${ }^{5} 21$ Anos; In: SONDELLI, 2010, p. 111).

[...] e tinha alguns inclusive que me discriminavam, aliás, tinham uns que diziam "Ah, essa aí não vai conseguir se formar nunca no $2^{\circ}$ grau". Eu tava conseguindo notas melhores do que eles. Só em algumas provas que dava alguns probleminhas, tipo de eu ir mal, a prova valer 10, e eu tirar 4. (Paula, 43 anos; In: CARNEIRO, 2007, p. 99).

[...] muita gente dizia que não daria certo. Porque... já me conheciam e achavam que eu não tinha capacidade (Ivan, 31 anos; In: CARNEIRO, 2007, p. 71).

As experiências narradas por esses sujeitos mostram a força das limitações atribuídas às pessoas com deficiência intelectual, por conta do estereótipo da impossibilidade de aprender ou se desenvolver. Nesse sentido, é preciso "pensar que a deficiência não está 
http://dx.doi.org/10.5902/1984686X33882

na pessoa, mas emerge nas práticas sociais e que toda pessoa independente de sua condição se desenvolve, tenciona o discurso hegemônico cuja essência biológica é suprema e definitiva" (SILVA; SILVA, s/d, p. 5).

Frente a esta postura, pessoas com deficiências se defrontam, constantemente, com o desafio de provar que têm capacidade de desenvolver diferentes habilidades e resistir ao descrédito social como evidenciam as narrativas abaixo:

Será que ele vai ter capacidade? Será que vai ter como... As pessoas estão sempre duvidando da minha capacidade, estão sempre duvidando. E eu sempre preciso provar aquilo que eu preciso fazer (Ivan, 31 anos; In: CARNEIRO, 2007, p. 73).

Eu ia desistir [...], mas eu não podia parar enquanto não ficasse de maior, não fizesse 18 anos [...] eu achava que não ia chegar até aqui. Achava que não ia conseguir chegar. As pessoas falava que eu não [pausa grande na fala] [...] Tem muita gente que falava para eu parar de estudar na quarta série. Meu pai falava, mas eu não quis; eu quis chegar até o final". (Beto, 23 anos; In: ANTUNES, 2012, p. 90).

Outra narrativa é um exemplo de como é marcante o estigma de deficiente intelectual, sobretudo, nos casos, como a Síndrome de Down, em que a condição é fenotipicamente detectável $^{6}$, ou seja, pode ser identificada de imediato, produzindo atitudes de discriminação.

[...] Porque ninguém queria me aceitar, porque eles viam as minhas dificuldades... físicas, né? Tinha que ter... até para entrar na escola tinha que ter laudo médico. O pessoal das escolas via que eu era Síndrome de Down, e não queriam me aceitar. A partir daí começou a discriminação (Paula, 43 anos; In: CARNEIRO, 2007, p. 94).

Essas experiências, infelizmente, frequentes no decorrer da vida social do indivíduo, podem cristalizar a internalização da incapacidade de aprender, produzindo baixaautoestima e conformismo com uma vida limitada e pouco desafiadora. Nas palavras de Glat (2006, p. 31), "pessoas portadoras de deficiências, assim como de outros tipos de estigma são, como visto, socializadas de maneira estereotipada, de acordo com o rótulo que Ihes é outorgado".

\section{Autopercepção da deficiência}

Conforme discutido, compreende-se a deficiência como produção histórico-cultural permeada, mesmo em plena vigência das políticas de inclusão, pela representação social da incapacidade, desvio, anormalidade. Embora esta situação de preconceito e discriminação seja compartilhada por outros grupos marginalizados, no caso das pessoas 
http://dx.doi.org/10.5902/1984686X33882

com deficiência, sobretudo intelectual, como lembra Glat (2006), o quadro é mais grave, pois a violação da norma (padrão físico e /ou comportamental), além de ser facilmente detectável, é permanente e independente da cultura ou momento histórico.

Uma das questões que norteiam a presente pesquisa é compreender como jovens e adultos com deficiência intelectual entendem a sua própria condição originadora do estigma. Nos cinco estudos aqui considerados, os sujeitos demonstram ter percepção de uma prática social diferenciada, a partir de seus relatos em diferentes situações:

No princípio as pessoas ficavam olhando com uma diferença, mas eu me adaptei bem porque eu sempre fui de falar demais, aí eu me adaptei bem. [...] Eles ficam falando de mim né, por que ela pode isso e a gente não pode. Isso às vezes é chato. Por que eu posso consultar o meu caderno, aí eles ficam assim porque ela pode e eu não posso? Eu também não gosto disso, mas fazer o que se eu não consigo manter as coisas na minha cabeça? Aí é chato ficar escutando eles falarem e saber que é de você [...] Ninguém gosta de ser diferente né, mas é [...]. (Luci, 19 anos; In: ANTUNES, 2012, p. 115 e 117).

Rodrigo: Se você perguntar pra mim "Você se acha especial?", eu respondo: "Em algumas coisas sim". Daí: "Pra quê?" "Eu não posso dirigir, não posso andar sozinho na rua...". Mas isso se me perguntar, porque se não perguntar eu deixo quieto. Agora, se vier com pergunta meio besta...

Pesquisador: Tipo o quê?

Rodrigo: Tipo, "Você se importa de ser pessoa especial?" "Eu não!",

Pesquisador: "E como é pra você?"

Rodrigo: "Ué, normal". Eu tenho meus amigos, faço tudo. Eu trabalho, eu pinto. Se bem que agora não tô na ativa... E falam que pessoa especial não pode trabalhar... (Rodrigo, 30 anos; In: LOPES, 2012, p. 10).

O pessoal da minha turma tem 14 anos e eu tenho 19 [...] É, isso sempre aconteceu comigo. No começo era tudo criança e aí não fazia diferença, mas agora eu to ficando adulta e eles tão começando aonde eu já passei. (...) Eu não converso, eu não sou muito de conversar assim. Eu era muito de conversar, mas agora que eu cresci eu não sou muito de conversar mais não. Às vezes eles não vão entender, por eles serem melhores do que eu ele podem não entender, então o que adianta eu falar se eles não vão entender (Luci, 19 anos; In: ANTUNES, p. 93).

Nas falas os sujeitos exprimem abertamente sobre sua deficiência, indicando consciência dos impactos negativos, decorrente da representação social estigmatizada.

Alguma vez alguém te perguntou se tu tinhas Síndrome de Down?

Sim.

E o que tu respondeste?

Que não, que eu não tinha,

Como assim?

Sim, eu tenho, mas não digo.

Por quê?

Porque eu não me considero com Síndrome de Down. Eu não me sinto com Síndrome de Down.

[...] Tu não achas que seria melhor tu falar que tem a Síndrome? 
http://dx.doi.org/10.5902/1984686X33882

Não, porque as pessoas não pensam como tu. Tu achas que eu vou dizer que tenho Síndrome de Down? Aí mesmo que vão duvidar da minha capacidade. (Ivan, 31 anos, In: CARNEIRO, 2007, p.78).

Tu te sentes uma pessoa deficiente?

Não, não é deficiente. Eu me sinto uma pessoa limitada. Dificuldades para fazer algumas coisas (Paula, 43 anos; In: CARNEIRO, 2007, p.100).

Eu, não, mas a sociedade sim me considera um deficiente mental, porque consideram Síndrome de Down, como uma deficiência mental. Então, claro, um deficiente mental para as leis, não pode fazer concurso. (LEÓN, 32 anos; In: CARNEIRO, 2007, p.162)

As narrativas acima evidenciam que os sujeitos têm autopercepção de sua condição de deficiência intelectual. No entanto, também se pode vislumbrar como a representação social de deficiência como incapacidade está presente nos diálogos, e os sujeitos desenvolvem diferentes estratégias para lidar com este estereótipo, inclusive, através da negação da condição. Nesse sentido, concordamos com Carvalho (2008) ao dizer:

Apesar dos esforços, inclusive das próprias pessoas em situação de deficiência, não é nada fácil desemaranhar os efeitos das práticas discursivas que apresentam suas diferenças como desqualificação, porque elas não se enquadram num processo de identificação com o padrão aceito e valorizado como ideal (CARVALHO, 2008, p. 21).

\section{Autopercepção do preconceito}

Como já apontado, à pessoa com deficiência intelectual é imputado o estigma de incapaz, o que acarreta desvalorização social. E é justamente esta relação entre estigma e desvalorização social que gera preconceito. Nas palavras de Piccolo (2015):

Indubitavelmente, a forma como nos relacionamos com as pessoas em situação de deficiência está influenciada, na maioria dos casos, pelas experiências baseadas em conotações que imprimimos a definição da deficiência, a qual tem se erigido pela recepção de uma enorme quantidade de preconceitos por parte da sociedade que impõe uma suposta inferioridade biológica e fisiológica sobre as pessoas com deficiência em comparação com aquelas consideradas normais (PICCOLO, 2015, p. 154).

As narrativas dos sujeitos com deficiência intelectual, extraídas do conjunto de estudos analisados, evidenciam situações cotidianas explícitas de preconceito por parte de colegas e professores.

Aqui na escola eu sinto um pouco de preconceito. Nas ruas ninguém fala comigo, ninguém mexe comigo, também eu não sou de falar com ninguém que eu não conheço. Meu caminho é o caminho de casa e o caminho da escola. [...] eu acho que a gente, por exemplo, eu que dizem que tenho um pobreminha, tá. Você quer que eu tenho um pobrema? Eu que tenho um pobreminha sou especial! [...] Assim, se quiser ser meu amigo ser, se não quiser ser minha amiga não ser, mas também não joga e não tenha 
http://dx.doi.org/10.5902/1984686X33882

preconceito comigo. [...] É, tem gente que tem preconceito e faz piadinha? Tem. Sempre vai ter. Mas também tem gente que fala com a gente normal. Eu acho que sempre vai ter um lugar que vai ter um olhar pra gente com um olho torto. Eu acho que a gente não devia olhar tanto pra isso e olhar pra si mesmo e olhar pras pessoas que te amam ao redor (D, 27 anos; In: CASTANHEIRA, 2014, p. 97).

Então falam que eu sou um reloginho, que ninguém vai gostar de mim... que eu sou muito feia, que a minha bunda é mole, que o quadril é mole. Ah, um monte de coisa. Um monte de piadinha assim.[...] A N (nome da colega) ficou jogando piadinha lá no coisa, lá no ponto. E esse ga... como esse... eu falei... dei as costas e ninguém me viu chorando porque ia ser mais um motivo de piada. Mas eu estava de costas chorando. Mas eu acho que é... Viver a vida. Sei que vai ter piadinha sempre. Fazer o quê? Tem que conviver com isso. Eu sou sensível? Sou. Sou chorona? Sou. Sou gordinha? Sou. Uso óculos? Uso. $E$ eu não vejo nenhum problema. Sou mais feliz ainda. $E$ quanto mais falam de mim, mais eu apareço (D, 27 anos; In: CASTANHEIRA, 2014, p. 98).

É, é. Eu tô na feira de ciências com o L. F., D., M., N., M.. E, e, e, e não esse aí não gosta de fazer trabalho comigo não. [...] Falam que eu não sei fazer nada, que eu sou um burro. [...] Eu é... Eu Fico triste [...] Quando eu tô na fila da merenda eles saem de perto de mim, e vão lá para o final da fila. Se eu entro no refeitório, se eu sentar perto deles, eles sentam em outro lugar e na biblioteca também, se eu sentar perto deles eles vão sentar em outro lugar (Davi, 17 anos; In: ANTUNES, 2012, p. 115).

Dois aspectos se destacam nos depoimentos apresentados. Primeiro é que, contrariando o estereótipo, os sujeitos parecem ter plena consciência de sua condição, das limitações objetivas e sociais que acarreta e conseguem perfeitamente relatar suas experiências e expressar seus sentimentos. Segundo, também se percebe, nas falas, um movimento de resiliência e empoderamento. Para Dantas (2011, p. 35), empoderamento se "constitui um processo de desenvolvimento de potencialidades individuais, visando tornar a pessoa capaz de direcionar a sua vida de acordo com os seus sonhos e desejos". Nesse sentido, essa dinâmica possibilita ressignificar a construção da identidade social, provocando movimento de ruptura de rótulos, decorrentes da produção social da deficiência.

No entanto, por vezes, o preconceito se materializa em forma de bullying ${ }^{7}$. De fato, pessoas com deficiência sofrem no seu dia a dia variadas formas de violência, veladas ou não, físicas e/ou simbólicas. A "dinâmica do bullying está no preconceito, na discriminação e na intolerância ao diferente" (ARROIO; ZANUNCINI, 2012, p. 2). A vítima do bullying geralmente é um indivíduo mais fraco, e que, de uma forma ou de outra, não se enquadra nos padrões hegemônicos do grupo. Relatos a seguir, exemplificam situações de bullying:

[...] se chamava Rogério. Um nome feio demais. Fisicamente era muito feio. E implicava muito comigo. Me insultava e me ofendia: "Ei mongolóide, você...não sei que..." Não era meu colega de classe, mas era aluno no 
http://dx.doi.org/10.5902/1984686X33882

colégio. Implicava comigo quando meus colegas não estavam. (León, 32 anos; In: CARNEIRO, 2007, p. 130-131).

Então, comecei a Pedagogia Séries Iniciais. Daí começou uma outra discriminação dentro da Universidade. Inclusive tinha duas colegas da minha turma, das séries iniciais que me discriminavam. Pra elas eu era um lixo [...] (Paula, 43 anos; In: CARNEIRO, 2007, p. 104).

Beto diz que "com os colegas foi bom, eles não me desrespeitaram, só alguns". Mais adiante, após uma longa pausa complementa "Tem dois colegas na minha sala que não. Ficam mexendo no meu pescoço que eu não gosto. No curso é a mesma coisa, eles fazem curso comigo" (Beto, 23 anos; In: ANTUNES, p. 118).

Essas situações não passam despercebidas pelas pessoas com deficiência, e suas vozes denunciam a violência e sofrimento em situações concretas de preconceito.

\section{Considerações finais}

Como mencionado, no levantamento de produções científicas sobre autopercepção de pessoas com deficiência intelectual, poucos textos apresentaram as falas desses sujeitos. Apesar do número reduzido de narrativas, o objetivo deste estudo foi compreender, a partir das falas de jovens e adultos com deficiência intelectual sua autopercepção em relação à deficiência, ao estigma e ao preconceito. Consideramos que no imaginário social a categoria deficiência intelectual é considerada sinônimo de falta de inteligência ou incapacidade de aprendizagem, improdutividade, entre outros atributos que produzem a desigualdade e exclusão dessas pessoas em diferentes espaços da sociedade.

De fato, um dos estereótipos frequentemente associados à deficiência intelectual é "sua aparente incapacidade de analisar sua vida e expressar seus sentimentos, de dizer quem são e o que desejam" (BOGDAN; TAYLOR, 1976, apud GLAT, 2009, p. 21). Consequentemente, devido à produção social da deficiência, historicamente pessoas com deficiência intelectual não têm tido oportunidade de suas vozes serem ouvidas, sendo suas reinvindicações e necessidades levadas pelos familiares e profissionais, que representam intermediários na relação com o mundo social. "Cristaliza-se, assim, um círculo vicioso: não se dá espaço para o indivíduo com deficiência mental falar - e ele fica calado --, continua-se falando por ele, pois ele não tem nada a dizer." (GLAT, 2009, p. 25-26).

A partir das vozes das pessoas com deficiência intelectual, pode-se identificar sua autopercepção do contexto social que Ihes atribui um rótulo ou marca estigmatizada. Porém, os sujeitos também manifestam resiliência e um processo de ressiginificação de sua autoimagem, superando a visão de deficiência intelectual pautada numa concepção orgânica. 
http://dx.doi.org/10.5902/1984686X33882

\section{Referências}

AMERICAN ASSOCIATION ON INTELLECTUAL AND DEVELOPMENTAL DISABILITIES- AAIDD. Intellectual disability: definition, classification, and systems of supports. Washington, DC: AAIDD, 2010.

ANTUNES, Katiuscia Cristina Vargas. História de Vida de alunos com deficiência intelectual: percurso escolar e a constituição do sujeito. Tese (Doutorado em Educação), Universidade do Estado do Rio de Janeiro, Rio de Janeiro, 2012.

ARROIO, Sônia Pingoello; ZANUNCINI, Ivonete. A Dinâmica do Bullying na Educação Inclusiva. Curitiba: Faculdade Bagozzi, 2012.

BRASIL. Convenção sobre os Direitos das Pessoas com Deficiência (2007). Convenção sobre os Direitos das Pessoas com Deficiência: Protocolo Facultativo à Convenção sobre os Direitos das Pessoas com Deficiência: decreto legislativo nำ 186, de 09 de julho de 2008: decreto $n^{\circ}$ 6.949, de 25 de agosto de 2009. 4. ed. revisada e atualizada. Brasília, 2011.

CARNEIRO, Maria Sylvia Cardoso. Deficiência mental como produção social: uma discussão a partir de histórias de vida de adultos com Síndrome de Down. Tese (Doutorado em Educação), Universidade Federal do Rio Grande do Sul, Porto Alegre, 2007.

CARVALHO, Rosita Edler. Escola inclusiva: a reorganização do trabalho pedagógico. Porto Alegre: Mediação, 2008.

CASTANHEIRA, Andréa de Oliveira. Deixa que eu falo: a inclusão sob a ótica do estudante com deficiência intelectual. Dissertação (Mestrado em Educação). Universidade Federal do Rio de Janeiro, Rio de Janeiro, 2014.

CHICON, José Francisco; SÁ, Maria das Graças Carvalho Silva. A autopercepção de alunos com deficiência intelectual em diferentes espaços - tempos da escola. Revista Brasileira da Ciência do Esporte, v. 35, n. 2, p. 373-388, abr./jun. 2013.

DANTAS, Taísa Caldas. Jovens com deficiência como sujeitos de direitos: o exercício da autoadvocacia como o caminho para o empoderamento e a participação social. Dissertação (Mestrado em Educação). Universidade Federal da Paraíba, 2011.

FANTE, Cleo. Fenômeno bullying: como prevenir a violência nas escolas e educar para a paz. Campinas: Verus Editora, 2005.

FÉDIDA, Pierre. A Negação da Deficiência: a instituição da diversidade. Rio de Janeiro: Achiamé \& Socius, 1984.

FONTES, Rejane de Souza; PLETSCH, Marcia Denise; BRAUN, Patricia; GLAT, Rosana. Estratégias pedagógicas para a inclusão de alunos com deficiência intelectual no ensino regular. In: GLAT, R. (Org.). Educação Inclusiva: cultura e cotidiano escolar, p.79-96. Rio de Janeiro: 7 Letras, $2^{2}$ ed. revisada, 2015. 
GESSER, Marivete; NUERNBERG, Adriano Henrique; TONELI, Maria Juracy Filgueiras. A contribuição do modelo social da deficiência a Psicologia Social. Psicologia \& Sociedade. v.24, n.3, p. 557-566, 2012.

GLAT, Rosana. Auto-defensoria: movimento de auto-determinação e autonomia das pessoas com deficiência mental. In: Anais do 9o Congresso Estadual das APAEs de Minas Gerais. p. 1-8. Belo Horizonte/MG, 2004.

GLAT, Rosana. A integração social dos portadores de deficiência: uma reflexão. Rio de Janeiro: 7 Letras, 2006.

GLAT, Rosana. Somos iguais a vocês: depoimentos de mulheres com deficiência mental. $2^{\underline{a}}$ edição revisada. Rio de Janeiro: 7 Letras, $2^{\underline{a}}$ edição revisada, 2009.

GLAT, Rosana. Falando de si: estudos sobre autopercepção e histórias de vida de pessoas com deficiência intelectual. Projeto de pesquisa, CNPq, 2015.

GOFFMAN, Erving. Estigma: nota sobre a manipulação da identidade deteriorada. 4.ed, Rio de Janeiro: LTC, 2008.

LOPES, Pedro. "Deficiência intelectual" e identidade: notas a partir de trajetórias pessoais. Anais da 28ª Reunião Brasileira de Antropologia. São Paulo: 02 e 05 de julho de 2012.

NUNES, Leila Regina d'Oliveira de Paula et al. O que revelam as teses e dissertações sobre a autopercepção do portador de necessidades especiais? Temas em Psicologia da SBP. Vol. 10, nº 2, p. 135-154, 2002.

OMOTE, Sadao. Deficiência e não-deficiência: recortes do mesmo tecido. Revista Brasileira de Educação Especial. v. 1, n. 2, p. 65-73, 1994.

ORGANIZAÇÃO DAS NAÇÕES UNIDAS (ONU). Convenção sobre os Direitos das Pessoas com Deficiência. Doc. A/61/611, Nova lorque, 2006.

PICCOLO, Gustavo Martins. Por um pensar sociológico sobre a deficiência. Curitiba:Appris, 2015.

REDIG, Annie Gomes. Inserção profissional de jovens e adultos com deficiência intelectual. Curitiba: Appris, 2016.

SILVA, Glaucia Eunice Gonçalves da; SILVA, Rosivete Oliveira. Desenvolvimento humano, deficiência intelectual e as disputas por significação no campo discursivo. [s./d.]. Disponível em: https://wp.ufpel.edu.br/legadolaclau/files/2015/07/Glaucia-EuniceGon\%C3\%A7alves-da-Silva.pdf. Acessado em 12 de fevereiro de 2018.

SODELLI, Fernanda Guilard. Questões invisíveis e as histórias contadas por jovens: deficiência intelectual e vulnerabilidade ao HIV/AIDS. (Mestrado em Distúrbios do Desenvolvimento), Universidade Presbiteriana Mackenzie, São Paulo, 2010. 
http://dx.doi.org/10.5902/1984686X33882

SPINDOLA, Thelma; SANTOS, Rosângela da Silva. Trabalhando com a história de vida: percalço de uma pesquisa (dora?). Revista Escola de Enfermagem da USP, São Paulo, p. 119-126, 2003. Disponível em: http://www.scielo.br/scielo.php?pid=S008062342003000200014\&script=sci_abstract. Acesso em: 28 de julho de 2018.

VELHO, Gilberto (Org.). Desvio e divergência: uma crítica da patologia social. Rio de Janeiro: Zahar, 1985.

\title{
Notas finais
}

\begin{abstract}
${ }_{1}^{1}$ Pesquisa, em andamento, com financiamento do CNPq (bolsa de produtividade em pesquisa - PQ1 e bolsa de iniciação científica- PIBIC) e FAPERJ (Cientista do Nosso Estado- CNE), realizada no Programa de Pósgraduação em Educação da Universidade do Estado do Rio de Janeiro, sob coordenação da terceira autora. Aprovada pelo Comitê de Ética protocolo n. CAAE 57974116.1.0000.5282. Para maiores detalhes ver www.eduinclusivapesq-uerj.pro.br.
\end{abstract}

${ }^{2}$ A definição de deficiência intelectual atualmente reconhecida (AAID, 2010) se baseia no modelo global do funcionamento humano, o qual leva em consideração o contexto em que o sujeito se encontra, habilidades intelectuais, comportamento adaptativo, saúde e participação, além dos suportes necessários para o desenvolvimento integral do indivíduo (REDIG, 2016).

${ }^{3}$ Autoimagem ou autopercepção é aqui compreendida "como modos de simbolização/percepção que o sujeito constrói sobre si a partir dos processos de interação social vividos em diferentes contextos (concretos e/ou simbólicos) presentes em nossa cultura". (CHICON; SÁ, 2013, p.373).

${ }^{4}$ Aprovada no Brasil em 2009 pelo Decreto 6.949 (BRASIL, 2011).

${ }^{5}$ Todos os nomes são fictícios. O registro corresponde ao utilizado pelos autores dos estudos coletados.

${ }^{6}$ De acordo com Goffman (2008), o estigma pode assumir a dupla significação de desacreditado e de desacreditável. No primeiro caso, as características típicas do estigma são imediatamente identificáveis, o que leva, frequentemente a uma pronta rejeição; já no segundo, as características típicas só são perceptíveis com o convívio, ou dependendo da situação. Essas condições trazem diferentes percursos sociais aos indivíduos.

${ }^{7}$ Conforme Fante (2005), o bullying se caracteriza por práticas agressivas e conscientes destinadas a outrem, realizadas repetidas vezes, por uma ou mais pessoas, se concretizando em agressões que podem ser verbais, físicas e/ou psicológicas, como: ofensas, apelidos, intimidações, fazendo com que a vítima tenha danos, tanto psíquico quanto físicos, morais, materiais e emocionais.

\section{Correspondência}

Joab Grana Reis - Universidade do Estado do Amazonas, Avenida Djalma Batista, n. 2470, Amazonas, Manaus - Brasil.

CEP: 69050-010.

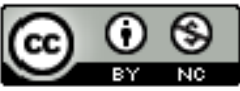

This work is licensed under a Creative Commons Attribution-NonCommercial 4.0 International (CC BY-NC 4.0)

Modalidade do artigo: Relato de pesquisa ( ) Revisão de Literatura (X) 